\title{
صعوبات التلاميذ فى تعلم اللغة العربية
}

$$
\text { بقلم : سرى سوديارتى }
$$

Prodi Bahasa dan Sastra Arab, Fak. Adab dan Humaniora UIN STS Jambi srisudiarti@uinjambi.ac.id

\section{التجريد}

كانت عملية التربية والتعليم سعيا مخططا لتشكيل تطوير قدرة التلاميذ كي تنفع لمصلحتهم نفسيا ومجتمعيا وشعبيا. وفي عملية تعلم التلاميذ ليس من النادر توجد عواعق

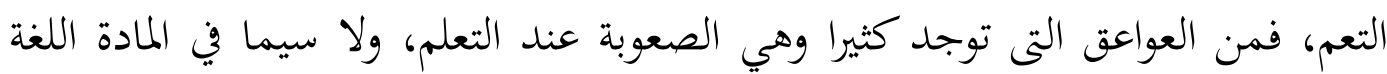

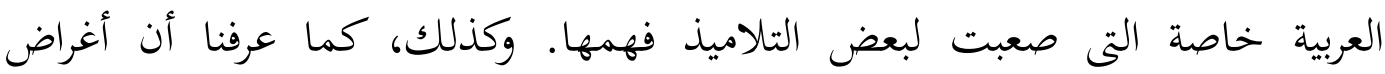
الأساسى فى تعليم اللغة العربية هي لترقية قدرة الطلاب في اللغة العربية، لسانا كان او كتابة. وفى هذا البحث سوف يبحث عن العوامل التى تكون مشكلة عامة في دراسة اللغة العربية لمتعلميها وكذلك يبحث أيضا عن محاولتها لتزيد مناهج التعليمة فن تعلم اللغة الأجنبية، خاصة في اللغة العربة.

تعميلية ويكون عنصورا أساسيا في الغالب في

\section{مقدمة}

تنفيذ كل جنس ودرجة التربية' . ان التربية في العصر الحاضر تواجه مشاكل مركبة التى يحتاج الى الإهتمام. وكانت هذه التربية تحدية للمدرس، بتطور المعرفة والتكنولوجية والثقافة الغربية التى تدخل في دائرة الابكار عموما.

' موحبين شه، فسيكولوجي بلاجار، جيليد با (جاكرتا :

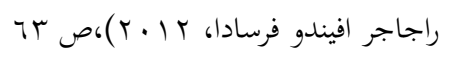
كان التعلم عمادا في التربية. لا تكون التربية بغير التعلم، لأن التعلم هو عملية للتغيير والتنشيئ. وكل الناس في طول حياتم معترفين كانو أم لا، قد يلزم عليهم التعلم دائما. فالتعلم يجعل الناس باقيا ثابتا في منافسة حياة الدنيا. والتعلم يكون نشاطة 
ليتملك قوة الروحي الدينى وضبط النفس والشخصية والذكية والأخلاق الكريمة والمهارات التى يحتاج إليها نفسه وبجتمعه وشعبه ودولتهَّ. إذن، التربية تغير موقف الناس من عدم الأدب إلى الحياة الادبية لأن التربية تنشئ كل نوحى النفس عبر تحويل القيم بطريقة التربية والتدريس والتدريب.

والتدريس هو مساعدة التلاميذ نيل الأخبار والأفكار والمهارات والقيم وطريقة التفكير والوسائل لتعبير نفسه وطرق التعلم وكيفية التعلمّ؛ فاصطلاح التدريس يملك حقيقة التخطيط والتصميم سعيا لتدريس التلاميذ. وذلك سببا في التعلم التلاميذ لا يكون التفاعل بالمدرس منبع التعلم فقد، وإنما التفاعل بكل منابع التعلم الآخر. و.يمكن الإختلاص أن منبع التعلم هو كل شيئ يعطى الأخبار والمعرفة والخبرة الى التلاميذ والمدرس في نشاطة التعليم كي تكون نشاطة

\footnotetext{
r ' آنونيم، حيمفونان فروندغ اونداغان ريفبليك إندونيسيا

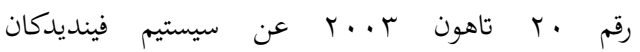

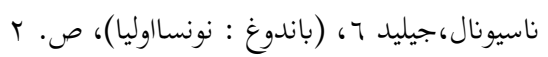

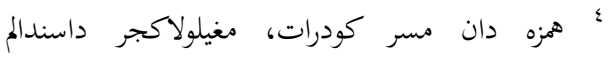

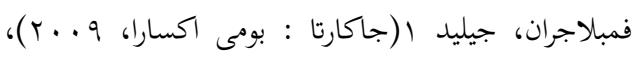
ص.
}

وينبى الناس أن يستطيع تربية نفسه وأهله وفي العموم المجتمع في بيئة حوله. وطبعا على فعل هذا، كي يكون التلاميذ غير متلوث بحضور الثقافات الغربية عبر التربية. أعتقدت أن التربية وسائل إستراتيجية لترقية رتبة حياة الناس. عبر التربية كان الناس ذاكيا ويملك البراعات وموقف الحياة الحسن حتى يستطيع المعاشرة حسنا بالمجتمع ويمكن النصر لنفسه. وقد عرفت التربية هي أعطى الرشيد الى الولد الذي لا يبلغ رشده لنيل الهدف، أعنى الأرشدية. والرشيد هو الذي يستطيع مواجهة مشكلات الحياة بقوة معرفته وخبرته وثبات دينه لأن الدين يكون قوة اساسية لتكوين الناس مستقيما بما ثبته • الخالق وفي القانون الجمهورية الإندونيسية النمرة • ب والسنة r . . ب عن عنظمة التربية الدولية في الفصل الأول والآية الأولى، أن المراد من التربية هي السعي إعترافا وخخططا لتحقيق الحال التعلم وعملية التعليم كي يكون التلاميذ فعليا ينشئون قوة النفوذ نفسه r ايعكوسوارا، الن قمرية، ادمنستراسي فنديديكان، (باندوغ

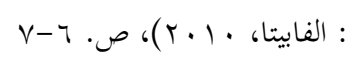


قانون الجمهورية الإندونيسية النمرة ع

والسنة ه . . ب عن المدرس والمحاضر تشرح ان

المدرس هو المربى المهنى بأولى الواجبات التربية

والتدريس والإرشاد والتوجيه والتمرين والتقييم

وتقدير التلاميذ في تربية الأطفال صغار السن

بخطط التربية الرسمية وتربية الإبتدائية و تربية

المتواسطة ه. المدرس هو قوة المهنى التى له مسؤولية للتربية و التدريس التلاميذ بخبرة بتملك بشكل الرسمية أم غير الرسمية. وعند رأي مولياسا، كما نقله مرتينيس يامين و ميساه أن المدرس له سهم كبير على نجاح التعليم في المدرسة.

الرغبة والقريحة والقدرة والأقوية التى

يملكها التلاميذ لا تنشئ أحسن بلا مساعد المدرس. في هذه العلاقة ينبغى للمدرس ان يهتم التلاميذ فرديا لأن بين تلميذ واحد مع تلميذ آخر إختلاف أساسى في الغالب. والمدرس يعطى الحث كي يكون التلاميذ

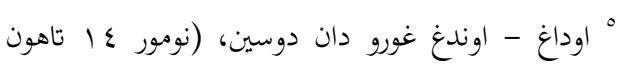

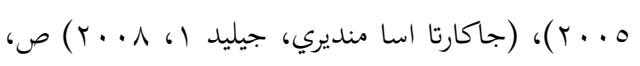

" مرتينيس يامين دان ميسة، مناجمين فمبلاجران كلاس،

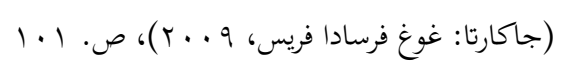

التعليم تباشر مؤثرا وفعالا وتحقيق هدف

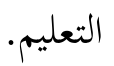

ويمكن منبع التعلم الكتب وآلة المعرض والرواية مثل المدرس والمحاضر والمؤلف وغير ذلك. ومنبع التعلم من البيئة مثل المستشفى وحديقة الحيوانات وغير ذذلك. والوسائل لك الإلكترونية مثل التلفاز والمذياع وغير ذلك. منبع التعلم له وظيفة ودور كبير في عملية التعليم والتعلم وهي تعطى الفرصة الى التلاميذ لتغنيةخبرة التعلم وزيادة المعرفة مباشرة. فنشاطة التعلم مثل هذا يمكن قيج تعليل التلاميذ للتعلم لوجود التفاعل بن التلاميذ

$$
\text { ومنبع التعلم. }
$$

كانت عملية التربية والتعليم سعيا

مخططا لتشكيل تطوير الملكة والقدرة كي تنفع لمصلحة الحياة نفسيا وبجتمعيا وشعبيا. كل أنشطة التربية لا يمكن الانتقال بسعي الذي يلزم فعله لتنشيئ الموارد الإنسانية المؤهلين والمؤمنين. وفي التربية لا يفك من التدريس لأن التدريس نشاطة المدرس وأولى واجباته التربية. وتعلق عن التربية يورط قوة التدريس المربى او المدرس. 
المدرس حافزا لتلاميذه يعطي الحث للتلاميذ كي يكون بالأحسن من قبل، وي شقاوة الاولاد كان مدرس الدينية أنسب الحافز، لأن عبر مدرس الدينية تدخل القيمة الدينية الى التلاميذ عن الحقوق الصحيحة وغير الصحيحة للعمل وآخره في أمر الدنيا والآخرة

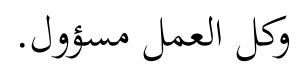

التعليل يفسر سعيا لتجهيز الأحوال

المعينة حتى يريد أحد أن يفعل شيئا. ويعطي التعليل جهدا للحفظ على حماسة تعلم التلاميذكي ينفذ التدريس بالأحسن. ويقصد التعليل جهدا للحث وتهيج التلاميذ ليعلموا الأنشطة وواجباتم بشعور الإعتراف لئلا يعلموا الشقاوة. وأهدف تنفيذ التعليل هي تغيير موقف التلاميذ مناسبة بإرادة المدرس، ترقية فمة التعلم، ترقية نظام التلاميذ، ترقية انجاز التلاميذ، ترقية اخلاق التلاميذ، ترقية شعور مسؤولية التلاميذ على الواجبات. التعليل مفيدة جدا لكل الإنسان ويمكن استخدامه لنيل أحسن الشخصية.

في تنفيذ عملية التعليم تنقسم إلى ثلاثة أقسام : التربة الرسمية والتربية غير رسمية والتربية
يشجع فعل الخير وتعويدهم للمسؤولية على

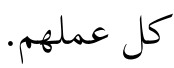

فراجودي أدموسوديرجو، يذكر أن المدرس له دور كبير في التربية، وفي كاهله حملت مسؤؤلية على جودة التربية. فمن ذلك، ينبغي للمدرس أن ينشئ نفسه بالمعرفة والمهارات التى أحتاج إليها في التدريس. ولذا، يلزم على المدرس أن يفهم تلاميذه لأول مرة. وفي التربية قد طلع الإسلام ويسيطر وينشئ الفكرة والخبر و واقع التربوية التى مناسبة بقيم الإسلام التى تستطيع توسط تخطيط برامج أنشطة العملية ولا سيما ما يتعلق بالتطوير وإنتفاع المعرفة والتكنولوجيا التى تكون سببا

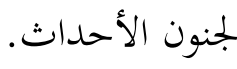

وينبغى للمدرسين أن يسابقوا في التدريس بإعطاء سهولة التعلم لكل التلاميذ، كي يستطيعوا تنشئة أقويتهم بالأحسن. وفي هذا، يلزم على المدرس أن يكون إبكاريا ومهنيا ومتمعا بوضع نفسه حافزا. واعطاء التبرعات العقل للوالدين لعرف مشكلة تواجهها التلاميذ واعطاء اقتراح حل المسئلة وبالخصوص في شقاوة الأولاد. وظيفة، كان 
المساهة الى الانتاج هي العملية، وهي تويل الطلبة مساهمة تقبل في المؤسسة أو وحدة التربية والخريج يكون إنتاج التربية.

للصعوبات أشكال متنوعة وبدافعة

متنوعة، طبعا على أن عملية التعلم بجرى

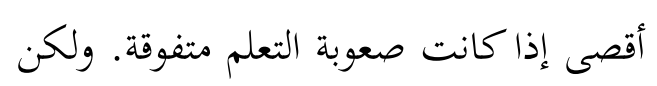
لاكتشاف الحلول على المشكلات السابقة، فقد أنبغى على معرفة التعريف والعوامل ومظهر صعوبات التعلم. فإذا كانت الصعوبة تكون سبيا لإنخفاض إنجاز التلاميذ ويعوق

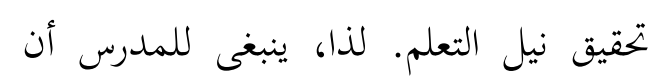
يعرف ويسيطر كيفية توفق صعوبة التلاميذ

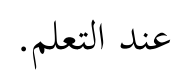

اللغة هي ادة المواصلة المستعملة لكل

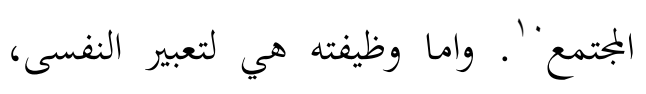
وادة المواصلات، ولاداء الاندماج وتكييف

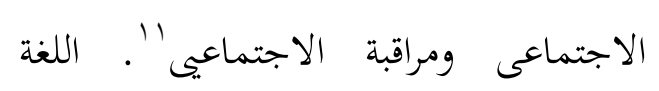

" سيفول سكا، ادمينستراسي فينديديكان كونتمفورير،

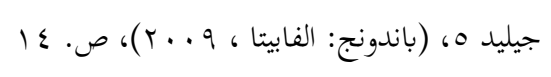

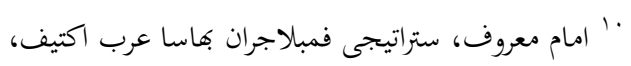

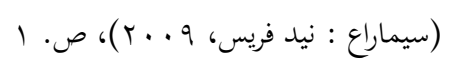

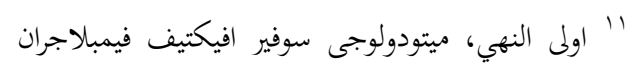

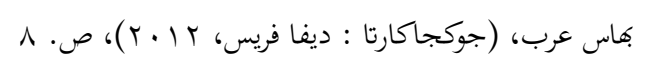

بدون الرسمية. وكانت التربية الرسمية تربية منظومة ومتدرجة مكونة من الإبتدائية

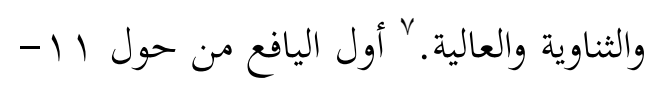

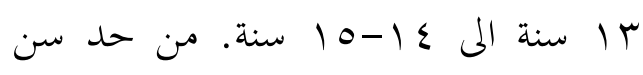

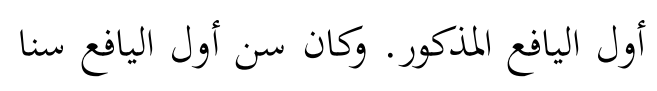

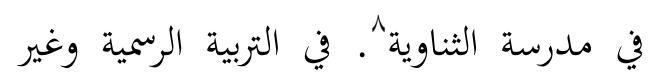
الرسمية كانت عملية التعلم مسؤولية المدرس الترس الترسية

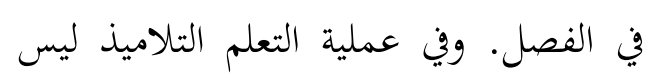

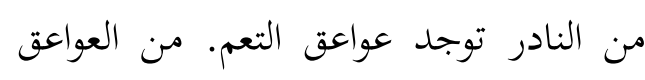
التى توجد كثيرا هي الصعوبة عند التعلم، ولا

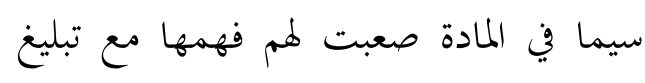
المدرس مسئم والطريقة الروتينية ووغير ذلك لهائ

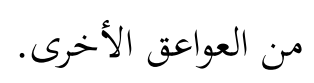

ولكن في تنفيذ عملية التعليم، يكصل كل فرد / طالب نتيجة متفرقة. وكثير منهم يواجه الفشل. وتحدث هذا خلفته قدرة

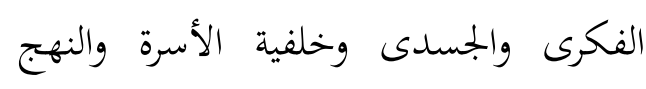
المفروقة بين تلميذ وتلميذ آخر، وغير ذلك، الصعوبات التى يواجهها الطلبة تكون اول

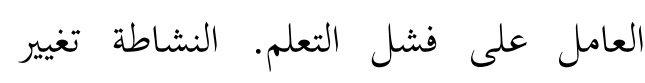
r اوداغ - اوندغ نو. .r ^ اينونج فاطمة، فيسيكولوجى فركمباغان (فيركمباغان

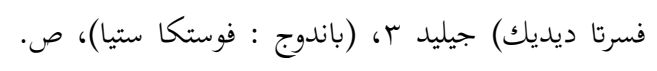
$1 \cdot r$ 
للشخص. 10 والمعنى الضيق، ان التعلم هو يقصد ان يكمن القبض بمواد العلوم التى هي جزء من الانشطة التى تؤدى الى تشكيل 17 شخصية كله. واما تعريف الدراسة الاساسية هي ما يلى :

ا ـ رأى مورغن الى استشهد بها في introduction to ) كتاب "(Psychology الباقي في السلوك الذي كان يحدث

$$
\text { في نتيجة التدريب والخبرة". }
$$

r. قال (Witherington) في كتاب

(Educational Psychology)

"الدراسة هي التغيير في السلوك الذي يظهر النفس بتجديد الحركة في الجملة والصفة والعادة والذكى

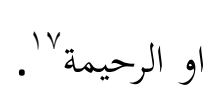

\footnotetext{
10 كشف الانوار اوس دان هيندرا هارمى،

فيرينجنأن سيستيم فيمبيلاجران كوريكولوم تيعكات ساتوان

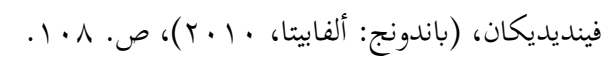

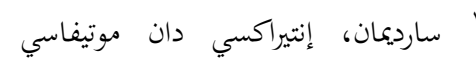

لبيلاجر معاجز، (جاكارتا: راجا غرافيندو فيرسادا)، ص. بـ

$$
. r \mid-r \text {. }
$$

IV عالم فوروانتو، فسيكولوجى فينديديكان،

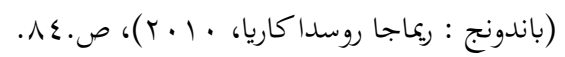

مقاصدهم. العربية هي الفاظ يعبر بها كل قوم عن

وكنا نعلم أن أغراض تعليم اللغة العربية هي لترقية قدرة الطلاب في اللغة العربية، لسانا كان او كتابة. واللغة العربية لها اربع مهارات، مهارات الاستماع و مهارة الكلام ومهارة القراءة ومهارة الكتابةج" . ومن الاربعة المهارات المذكورات ينقسم الى قسمين الاول مهارة الاستعبادية هي الاستماع والقراءة والثانى مهارة الابتكارية هي المحادثة والكتابة.

\section{أ. معنى تعلم اللغة العربية}

إنما أنشطة التعلم لا يتم فصلها ألا

بعملية التعلم. واما المعنى التعلم يمكن بتعريف نطاق واسع باعتباره الأنشطة النفسية والجسدية التى تؤدى الى تطوير كامل 
و. التغييرات يغطى جميع جوانب السلوك 19.

ولذلك ان تعلم اللغة العربية هو سعى

في قبض العلوم العربية التى هي جزء من الانشطة الرامية الم تشكيل الشخصية الكاملة الموافقة بعلامة الدراسة.

\section{ب. عملية التعلم}

بشكل عام، يتم تنفيذ عملية تعلم اللغة

العربية في ثلاث خطوات وهي الاولية والانشطة الاساسية وكذلك الانشطة

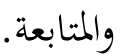

1. الانشطة الاولية. ويلزم فيها الاحماء

$$
\text { وادراك شعوري تشمل مايلى : }
$$

أ. يبدأ الدرس بالأشياء التى يعرفها

$$
\text { ويفهمها المتعلمون. }
$$

ب.نمى ورفع دوافع المتعلمين ليكون

$$
\text { إهتماما ومفيدة للمتعلمين. }
$$

ج. تشجيع المتعلمين لتكون مهتمة في

$$
\text { معرفة أشياء جديدة. }
$$

\footnotetext{
19

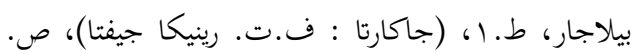

learning is a "(Geoch) وقال

change in performance as a resultof "practice"

فلذلك يمكن القول ان التعلم هو

الانشطة النفسية والجسدية التى تؤدي الى تطوير كامل للشخص، وهو اشراك عناصر الابداع، والذوق والخيال والمعرفية والوجدانية والحركية النفسية. ولذلك ايضا، يمكن ان يفهم عملية التعلم والتعلم فيها التفاعل المتعددة في الاتجاهات هو التفاعل بين المعلمين والطلاب، والطلاب مع وسائل

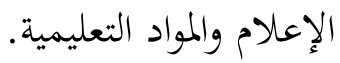
عوامل التعلم لها الخصائص التالية : أ. التغييرات التى تحدث بوعى. ب. التغييرات في الدراسة الوظيفية. ج. التغييرات في هذه الدراسة هي ايجابية ونشاطة. د. التغييرات في التعلم ليست مؤقتة. هـ. التغييرات في هدفت الدراسة أو

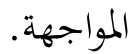


هي تشجيع الطلاب على تطبيق المتن والتعريف المعلوم في الحياة اليومية، ويبنى الطلاب الصفة والسلوك الجديدة في حياتا اليومية على أساس عرفها وعلمها ومنهجية هدابات الأنسب لتغيير موقف وسلوك

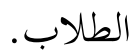

r. الانشطة الاخيرة والمتابعة ي الانشطة الاخيرة تعطى فيها لعمل

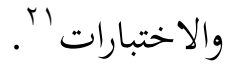
وين الوقت نفسه، ان قسم التربية الوطنية المقترحة قال ان في الانشطة الاخير يجب أن تنفذ مع إيلاء الاعتبار الواجب مما يلى أ. الطوير في طرق تقييم نتائج تعلم

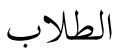

ب. استخدام نتائج التقييم لرؤية ضعف أو نقص في الطلاب والمشاكل التى تواجه

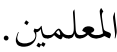
ج. ابحاث الطرق الصحيحة التى يواقف به الأهداف المراد 'ب ك.

"r بموليشاء، كوريكولوم بيرباسيس كومفيتنسي

: كونسيف، كاريكاتيرستيك دان إمفيليمنتاسي، (باندونج :

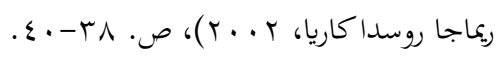

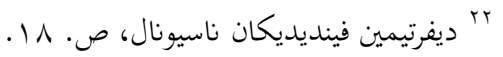

r. تشمل الانشطة الاساسية أنشطة

الاستكشاف وترسيخ التعلم، وتشكيل الموافق والسلوكك

أ. انشطة الاستكشاف السعى للحصول على معلومات جديدة. وويحتاج فيها ادخال المواد، وربط المواد مع المعرفة للطلاب الحاليين، وتبحث عن انسب منهجية في التحاق الطلاب سوف تزيد من مواد جديدة. ب. ترسيخ التعلم هو تحقيق معرفة جديدة. وفي ترسيخ التعلم يلزم فيه المحافظة مما يلى : الطلاب الانخراط بنشاط في تفسير وفهم المواد التعليمية الجديدة، والطلاب المشاركة بنشاط في حال المشكلات، ووضع التركيز على العلاقة الهيكلية، أي الصلة بين الموضوع الجديد مع مختلف جوانب الانشطة والحياة في البيئة، والبحث عن المنهج المناسب بحيث يمكن معالجة المواد التعليمية الم جزء من المعرفة للطالب ‘. ج. تشكيل سلوك الطلاب هو عملية التعريف في القيم والمواقف والسلوك،

\footnotetext{
r. r. كشف الانوار اوس دان هيندرا هارمى،

فيرينجنأن سيستيم فيمبيلاجران كوريكولوم تيعكات ساتوان

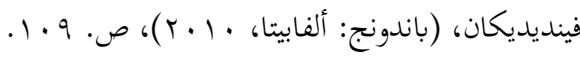


(توقيع)، التغر، حرف التج، النسخ، والخط

$$
\text { الخاص في الزمن الانجبr. }
$$

r. بالاملاء

في مهارة الاملاء يتطور ثلاثة مهارات، وهي الاملاء المنظور، الاستماع واليد العاطف في

$$
\text { r. الكتابة الانشاء. }
$$

الانشاء هو طبيقة / رتبة الكتابة الموجهة

على تعبير الفكرية وهي من النظرية، الوصية

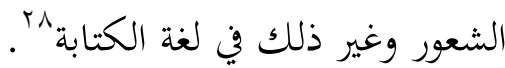

يوسف الخلفية ابو بكر ينقسم اهداف مهارة الكتابة مايلى : أ. ان يكتب ويحاكى جملا قصيرة

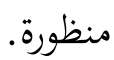

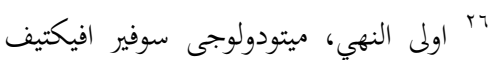

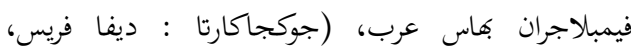

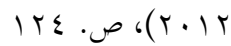

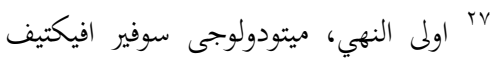

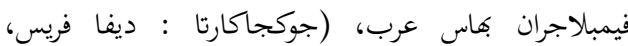

$$
\text { Irq. ص. (r. r }
$$

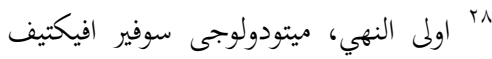

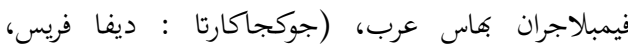

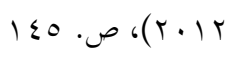

في كل مرحلة من مراحل التعلم السابق، فيحتاج الى رمز بتربة التعلم الحقيقة بموضوع التعليمrr

\section{ج. مهارة اللغة العببية}

واللغة العربية لها أربعة مهارات، مهارة الاستماع، مهارة الكلام، مهارة القراءة

ومهارة الكتابة ؟بك.

وفي تعليم اللغوى اي اللغة العربية، ان مهارة الكتابة تنقسم الى ثلاثة اقسام : منها الخط

$$
\text { والاملاء والانشاء }{ }^{\text {ro }}
$$

$$
\text { وعلى العموم ان الخط هو كتابة حروف }
$$$$
\text { العربية منفردا كان الحروف او مركبا بحرف }
$$

الاخر كتابة صحيحة وجميلة، ويناسب

بناحية وترتيب يقرره المخطات. وينقسم عبد

الفتاح الخاط الى ثمانية اقسام : الحوفي، الثلث، التعليق (الفارسي)، الديوانى، الاجازة

ك"rr كشف الانوار اوس دان هيندرا هارمى،

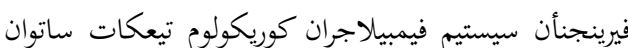

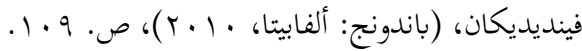
"2

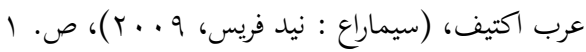

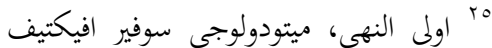

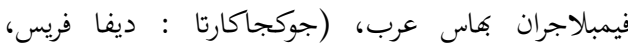


يساعدنا على تعلم مستمر بطريقة أسهل أو نقل التعلم 'بr.

أما الاهداف في تعلم اللغة العربية

نوعان هدف طويل الأجل (الأغراض العامة) والأهداف قصيرة الأجل (لأغراض خاصة). بشكل عام، ان تعلم اللغة العربية في إندونيسية خاصة هو لتفهيم القرآن والحديث، والكتب الصفراء الذي كتبه العلماء الكلاسيكية (السلفى)، بالإضافة الى المقصود أن الطلاب يمكن الاتصال باللغة العربية'”. اما الهدف الخاص هو الهدف المرجوة بقبضها من المادة الحالية. واما تعليم اللغة العربية بالمدرسة الثانوية منبع العلوم كوتا جمبى موافق للمعايير الكفاءة : وهي لمينية الاستماع والتحدث والقراءة والكتابة بَّ.

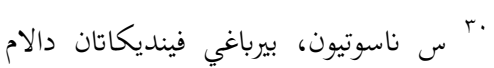

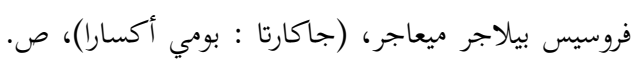

'ب جويريه دخلان، فاراديكما بارو فيمبيلاجران

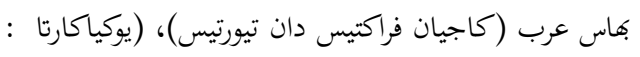

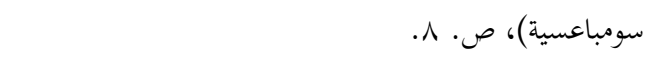
كب فوروم غوروا بينا ف أإ مدرسة عالية، مودول

بيرهاسا عرب كيلاس ·ل سيميستير غيناف، (سيراغين :

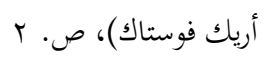

ب. ان ينمى الكتابة الاختبارية في حدود

التراكيب التى درسها.

ج. ان يستخدم المفردات التى درسها كتابة في تراكيب جديدة.

د. ان يكتب الطالب املائيا موضوعات لم

$$
\text { تسبق دراستها. }
$$

ذ. ان يتمكن الطالب من استخدام

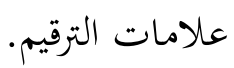

ر. ان يتمكن الطالب من التعبير الكتابى

\section{د أهداف تعلم اللغة العربية}

وفي عملية التعلم علامات واعداد

المركبة المرتبطة وكان له ايضا الهدف المراد

ليحقق هدف التعلم الموافق المرجوة من

خلال عملية المكونات المختلفة للتعلم.

وتحقيق هدف التعلم يحتاج الى ان يخلق بيئة

النظام (الاحوال) التعلم الافضل. وهذا

$$
\text { سيؤثر كثيرا على نتائج التعلم. }
$$

أما اهداف التعلم الاساسي هو ما كان

يعلمه مفيدة في زمن المستقبل، هو الذي

ب9 يوسف الخليفة أبو بكر، منهج التعليم

العربية للتعليم الاساسي في دول الساحل الافريقي،

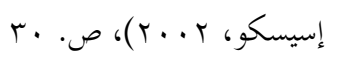


كما وضح في المناقشة السابقة ان الصعوبات في تعليم اللغة العربية بالمدسة الثانوية وعموما اها موافق بتعليم اللغة الاجنبية التى كانت غير لغة الام وفي النهاية اها مستخدمة للتشكيل عند المعلمين او الطلاب.

المشكلة التى يعانى احدهما كانت سببا في

عدم وجود سلاسة في عملية التعلم. والمعلم هو اكبر من تلاميذه، وهو يجب أن تكون قادرة على معالجة المواد ولا يكون مشكلة كبيرة للتلاميذ. واحد العوامل التى يمكن أن يصعب الطلاب على تعلم اللغة العربية هو لغة الكتابة العربية التى تختلف عن كتابة اللغة من الطلاب غيرهم، والكتابة اللاتينية؟r وللطلاب لن يكون هناك مشكلة في فهم ذلك، لانه من حيث أصوات اللغة وتشابه اللغة العربية اللغة الإندونيسية. من حيث الصوت بين اللغة العربية والاندونيسية قد اكتشف التشابه، والاختلافات، والتشابه

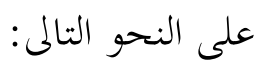

با" احمد عزان، ميتودولوجي فيمبيلاجاران بهاسا

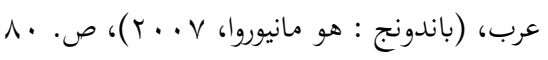

و. الصعوبات في تعلم اللغة العربية في

المدرسة الإعدادية (الثانوية)

الصعوبة مصدر من صعب - يصعب

- (sulit) $\cdot^{r r}($ kesulitan)

ان كل فرد مختلفة من حيث المبدأ. والفرق الفردية يسبب فرقا بين السلوك التعلم لدي الطلاب. ويمكن تفسير صعوبات التعلم احوال الطلاب الذين لا يمكنون ان يتعلمو بشكل جيدگّ. المثال، في تعلم اللغة كان اي الشخص الذي تعلم لغات أجنبية منها اللغة العربية سواجه صعوبة النحو المبين في شكل أخطاء، سواء في نظام الصوت، واستخدام المفردات أو بناء الجملة 'ror. ا ـ انواع الصعوبات في تعلم اللغة العربية

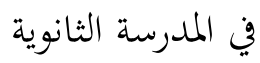

$\bar{~}$

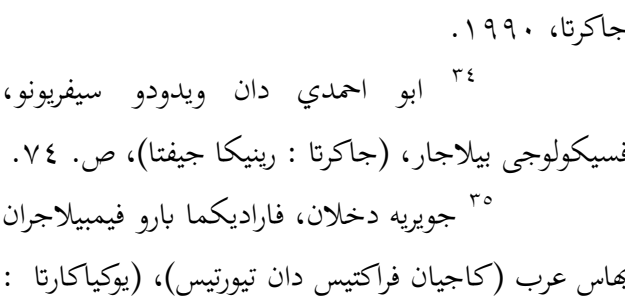
سومباعسية)، ص. 110. 
ب. لتسوية المخرج بل كان مختلفا في

صفته هي صاد ب S، الضاض ب d، الطاء

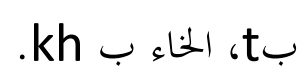

ت. لقرب المخرج والصفة وهي الغاء ب

$$
\text { g } 6
$$

في دراسة اللغة العبية، وسيصعب

الطلاب في نطق الصوت من اللغة العربية،

بال كان بين اللغة العبية والاندونيسية لديها

معادلات مبدأ أساسي، فيكون نطقه سهلا

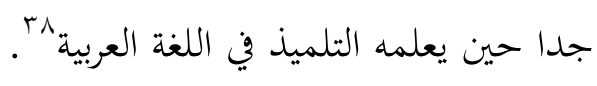

ץ. العوامل التى تؤثر الصعوبات في لي

$$
\text { تعليم اللغة العربية }
$$

العوامل التى تكون مشكلة في دراسة

اللغة العربية في هذه الرسالة العلمية وعلى نطاق واسع يمكن أن ينظر اليه في عاملين اثنين : العوامل الداخلية والعوامل الخارجية. نجحا كان الطالب في التعليم ام لا، هو قد اثره العوامل لتحصيل نتيجة الدرس وهو جاء من داخل نفس الطالب او من خارج نفسه.

عبد المعين، اناليسيس كونترا ستيف جهاس عرب دان

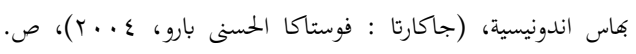

^.

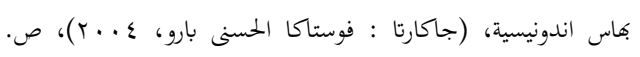

ا ـ التشابه بين الباء (ب) ب b، ميم

(م) ب m الفاء (ف) ب f، الزي (ز) ب Z، السين (س) ب S، الراء (ر) ب r، الدال (د) ب d، التاء (ت) ب t، اللام (ل) ب ال ، النون (ن) ب n، الشاء (ش) بsy، الياء (ي) ب ل)، الكاف (ك) ب k)، الهاء (ه) ب h، الواو (و) ب س أوجه التشابة بين ب// مع/ ب/،// م/

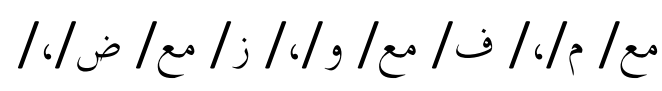
س/ مع//ق/،/ر// مع/ص/،// د/ مع/ د/،/ت// مع/ ر/،/ ل/ مع/ ل/، ن/ ن/ مع/ ن/، ش/ مع /سي/،/ي/مع/ص/، ك// مع/ لs/،/ هـ/ مع/ ح/،// و/ مع/ / ...

r. الفرق هو ان في اللغة الاندونيسية لا يكون هناك : أ. صوت المفخمة منها : /ص/، ض/،//ط/،/ ظ/،/ غ/،/ ق/،/ ج/

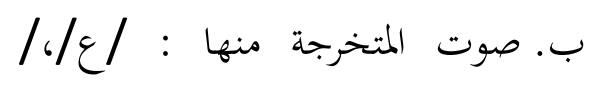

$$
\text { ح/،/ ظ/،/ ذ/،/ ث/ }
$$

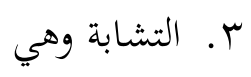

أ. لقرب المخرج (التعبير) وهي الذال

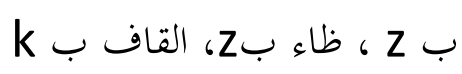


ان الرغبة تبلغ الى النتيجة الصحيحة،

فتلزم له الدفاع بثلاثة الأقسام الاتى :

ا ـ المعرف وهو قدرة تتعلق بالمعرفة

والمنطق أو الفكرة التى تتكون من فئة العلم والفهم والتطبيق والتحليل والتركيب والقدير.

r. الوجدانى وهو قدرة تفضل الشعور

والعاطفة والحركات التى تفرق بالمنطق الذي

يتكون من فئة القبول والمشاركة والتقييم/

تعيين الموقف والهيئة وتشكيل ونمط الحياة.

r. والحركية وهي قدرة تفضل المهارات

الجسمانية التى تتكون من الادراك والاستعداد والحركة المرشدة والحركة المتعودة والحركة المتركبة وتناسب نط الحركة والإبداع.".

واما الدفع عند سوماردي سوريا بتا

وهو حال في النفس الذي يدفع ان يعمل الانشطة المعينة لنيل المقصود '.

وعند Mc. Donald أما الدفع هو

تغيير النشاط من دخول النفس الذي يشار

•" سيفول ساغلا، ص. TI

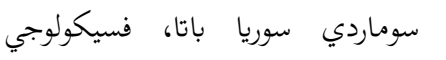

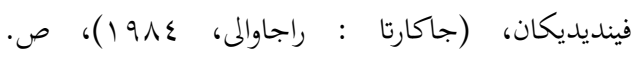
$(1.1) \mathrm{r}$.

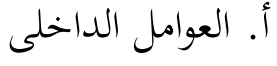

1 إل الصحة

هي الصحة الجسمانية والروحانية لما اثر كبير نحو قدرة التعليم. واذا كان الرجل مريضا دائما وصداعا وزكاما وحما فلا يحمس في التعليم. وكذلك اذا كان صحة الروحانية غير جيدة مثل تشويش الفكرة وخيبة الظن، فسينحفظ نشاطه في التعليم.

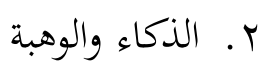

كانا مؤثرة جيدة على قدرة الطالب في التعليم. وعلى العموم اذا كان لاحد الذكاء (الاذكياء) فسيسهل في تعليم وله نتيجة جيدة. وبالعكس اذا كان ذكاؤه منخفضا فسيصعب في التعليم ويبطؤ في التفكير حتى كان انجاز تعلمه منخفضا ايضا. والموهبة كذلك، وله اثر كبير في تعيين

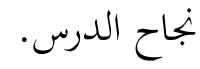

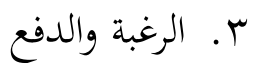

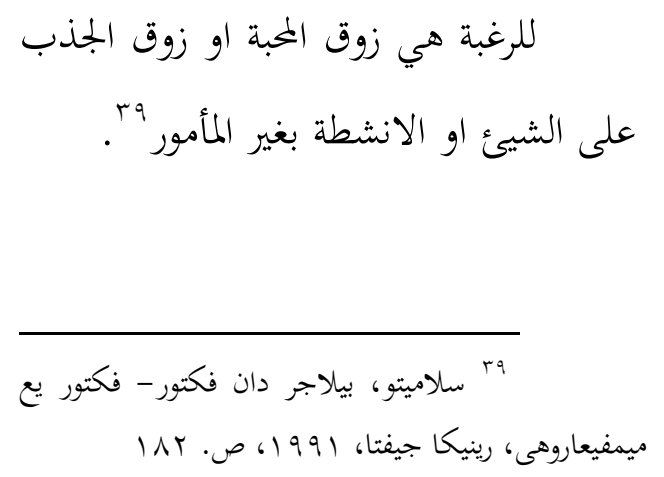


طريقة تدريسه، تناسب منهاج الدراسة بقدرة التلاميذ، حالة الادوات في المدرسة، حال الفصل، جملة التلاميذ على حسب الفصل، تنفيذ نظام المدرسة وغير ذلك، وهذه كلها تؤثر نجاح التلاميذ في التعليم.

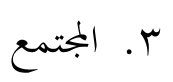

الجمتمع كان يقرر انجاز التلاميذ. اذا كان المجتمع الموجود في حول المسكن التلاميذ يتكون من الافراد المثقفة، اولاده وخاصة كانوا يتعلمون كثيرة في المدرسة العالية وهم اخلاق كريم فسيدفع التلاميذ الى النشاط الكبير في التعليم. وبالعكس ذلك، اذا يسكن التلاميذ في البيئة التى يسكن فيها الجهلاء الكثيرة ولا يتعلمون في المدرسة ويتعطلون عن العمل فسينخفض نشاط

$$
\text { التلاميذ في التعليم. }
$$

حالة البيئة التى يسكن فيها التلاميذ مهمة ايضا في تأثير انجاز التعليم. حالة البيئة بناية المنزل، حالة المجاورة، حالة المرور، الجو

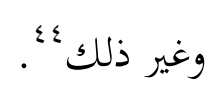

؛؛ عاليا سوريانى، ديكتات فيسيكولوجي،

$$
\text { rV-rr. }
$$

بظهور الاحساس ويبدأ بالإصغاء على الغرض (الهدف) ب؛ . والمقصود بالرغبة الحالة الحديثة إذا كان الشخص ينظر العلامة او المعنى، والحالة هي المواصلة بالارادة والاحتياج نفسه بـ؛ ع. ـ طريقة التعلم

طريقة التعلم كانت تؤثر على بلوغ نتيجة الدرس. التعليم بغير مراعاة الطرق وعلم العقلPsikologi والنفسى psikologi وعلم الطبيب سيحصل النتيجة غير المقنع.

$$
\begin{aligned}
& \text { ب. العوامل الخارجى } \\
& 1 \text { ـ العائلة }
\end{aligned}
$$

هي الاب والام و الابناء وقرابائهم الذي كانوا المقيمين في البيت. وللوالد اثر كبير نحو نجاح التلاميذ في التعليم.

$$
\text { r r المدرسة }
$$

حالة المدرسة التى تكون مكان التعليم تؤثر درجة نجاح التعليم. جودة المدرس،

rأ سارديمان، إنتيراكسي دان موتيفاسي لبيلاجر

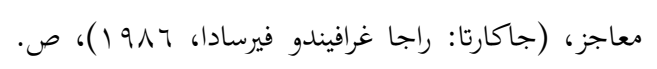
.Vr

rأ سارديمان، إنتيراكسي دان موتيفاسي لبيلاجر

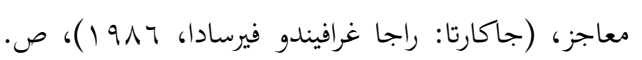
.$\vee 7$ 
المواتى بحيث يمكن انشطة التعلم للطلاب قد تغلبه على الشدائد. واما سعى في تغلب صعبة الطلاب يعتمد على المعلم الذي يربيه. ويعتقد كل الناس ان المعلم قد ساهم الى حد كبير في نجاح التعلم في المدرسة؛؛ ـالمعلم المثالى هو الشخص الذ تديم نفسها من خلال الدعوة دعوة روح الضمير، يريدون دائما ان يكون مع الطلاب داخل المدرسة وخارجها. وعندما ترى الطلبة إثبات مثل هذا الموقف المحزن، متقلب المزاج، العنيف، والكسل في التعلم ولا يذهب الى المدرسة والمريض وغير ذلك، ان المعلم يشعر خلقا شديدا، وفي الوقت الخاص قضى المعلم بعض وقته لتفمير تنمية الشخصية من طلابه 7 ك

دور المعلم وحاسمته مهمة شديدة لنجاح الطلاب، وبين ادوار المعلمين والواجبات الرئيسية هي المدرس، والمربى،

0؛ مرتينيس يامين دان ميسة، مناجمين فمبلاجران

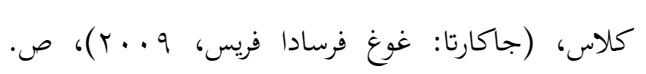
1.1

ب؛ سيف البحر دجاماراه، غورو دان اناك ديديك،

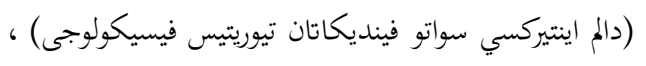

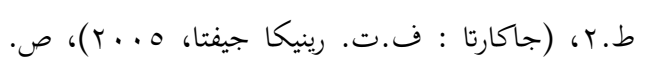
. $\varepsilon r-\varepsilon r$ r. السعي في حال الصعوبات عن تعليم اللغة العربية

في البحث السابق ان المشكلة في تعليم اللغة العربية كانت لها الطرق في التعامل أو تحليل مشكلة الطلاب لتكون منكشرة عنها. وفي البحث السابق ان العوامل في صعبة الطلاب في تعليم اللغة العربية كان يؤثره العوامل الداخلى والخارجي. التغلب صعوبة التعلم اللغة العربية على العوامل الداخلى، وفي تحديد وقيادة انشطة التعلم، يجب على الطلاب تحقيق التوازن بين امكانات المملوكة اللالذاتى ويمكن ان تكييف مع التعليم الذي يجري

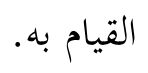
واما سعي التغلب الصعوبات في تعلم اللغة العربية من العوامل الخارجية، فيجب على ان العوامل التى ينطوى عليها قادرة على اثبات او دعم عملية التعلم لدي الطلاب وكانوا قادرين على القبول والتبادل نافعا. المحاولة لتحقيق هدف التعلم هو يحتاج الحلق بيئة النظام (الشروط) التعلم 
في تحقيق شيئ ". اختيار استراتيجيا التعلم المناسبة أمر ضرورى. وهذا هو، كيف يمكن للمعلم اختيار انشطة التعلم هي الاكثر فعالية وسيلة فعالة لخلق تحربة تعليمية جيدة، واحد التى يمكن ان توفر التسهيلات

$$
\begin{aligned}
& \text { للطلاب تحقيق أهداف التعليم. } \\
& \text { r. طرق التعلم }
\end{aligned}
$$

ويمكن تفسير أساليب التعلم كوسيلة

يمكن من خلالها تنفيذ الخطة التى تم اعدادها في شكل أنشطة حقيقية وعملية لتحقيق

$$
\text { ع. أهداف التعلم. }
$$

يمكن تعريف تقنيات التعلم كشخص

بطريقة التى تطبق طريقة محددة.

$$
\text { ه. تكتية التعلم }
$$

تكتية أسلوب التعلم الشخص في

تنفيذ أساليب معينة أو تقنيات التى هي

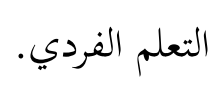

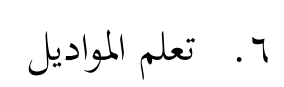

نموذج التعلم هو في الاساس شكل

من أشكال التعلم الذي ينعكس من البداية

الى النهاية وعادة ما يتم تقديمها من قبل

المعلم.
وكذالك وكالات بتحيدوتنمية المجتمع، والمعلم له دور متعدد في المربى المهنى حقول الحبرات

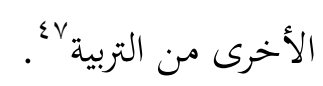

ويمكن أن يتم الجهود لتغلب الصعوبات التى تواجه الطلاب في تعلم اللغة العربية في عملية التعلم الاتى ^؛ ا ـ هنج التعلم (التقريب)

هج التعلم (التقريب) يمكن ان تفسر على اها نقطة انطلاقا او وجهة نظر من عملية التعلم، والذي يشير الى وجهة نظر من وقوع العملية التى مازالت شائعة جدا، والتى تسهل ومصدر الهام، وتعزيز وأساليب التعلم النظرى الأساسى مع تغطية خاصة.

$$
\text { r ـ ـ استراتيجيات التعلم }
$$

استراتيجيات التعلم لا تزال المفاهيمى

في الطبيعة، ويستخدم لتنفيذ بجموعة متنوعة من أساليب التدريس محددة. وبعبارة أخرى، فإن الاستراتيجية هي "خطة عملية تحقيق شيئ ما" في حين ان الاسلوب هو "وسيلة

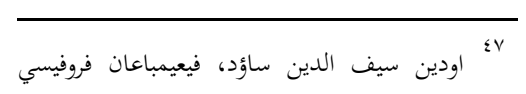

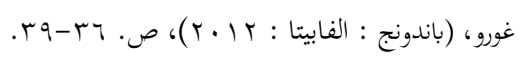

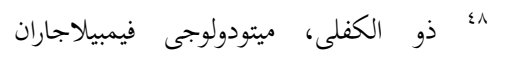

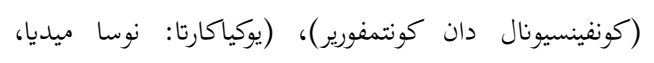

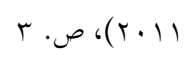




\section{r. دور الهندسة الرئيسية}

وهنا، يمكن للمعلم بزيارة المنزل لاحد

الطلاب. وهناك، يمكن المعلم رؤية بحرية،

وايلاء الاهتمام للطلاب من كل حوله. وهنا

يمكن للمعلم إجراء المحاورة المباشرة مع اولياء

الامور حول شخصية الطلاب والأسرة

والاقتصاد والعمالة وغيرها. بالإضافة الى

ذلك، يمكن للمعلم رؤية الدولة من المنزل،

$$
\text { والظروف والوضع مع الجمهور مباشرة. }
$$

ع. اختيار مهارات الاختبارات

\section{التشخيصية / / النفسية}

في هذه الحالة يمكن للمعلم تحديد

مدى الذكاء الشخص يمكن أن يظهر اليها

عن طريق الاجابة عن أسئلة عملية وبسيطة.

وبتدريب النفسي يمكن اتخاذها الطلاب

قيمة الشخصية المتعلددة من حيث الأساسية

والمنطق والخصوصية.

ه. تركيب برنامج التحسين

واول ما يمكن ان يركب البرنامج من

حيث المعلم. وينبغى أن يكون المعلم

كونسيفتور، واجهزة الإرسال والمحولات

والمنظمين. تم يستكمل بعض الدعائم او

الادوات الأخرى التى تدعم أفضل التدريس.
المحاولة الأخرى للتغلب على

صعوبات التعلم هي ما يلى

\section{ا ـ ـ مراقبة الفصول الدراسة}

وفي هذه المرحلة، قد تساعد المراقبة

الفصلية على تقليل الصعوبة من مستوى

الدراسة، المثال التفتيش من الحالة المادية

للفئة في أنشطة التعلم، ومريحة جدا، طازجة

وصحية وعلى قيد الحياة ام لا. كيفية

التحقيق، اذا كان جو الفصول الدراسية هو

مريح جدا وهادئة وصحية، ثم كل شيئ يمكن ان تحفز الطلاب على التعلم.

اهتم المعلم اهتماما جيدا بأن يرتب

ويقيد جو الفصل الدراسي. يمكن الطلاب

أن يتعلم بغير صعوبة، واتقان الدراسة التى

$$
\text { درسه المعلم بقيمة جيدة ‘. }
$$

\section{Y. تفتيش أداة الحواس}

في هذه الحالة يمكن ان تركز على

المستوى الصحي للطلاب محددة من

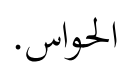

http://tentukanpilihanmu.weebly.com/cara -mengatasi-kesulitan-belajar.html

سوهرسيمي اريكونتو، داسار - داسار

ايفالوسي فينديديكان، ط. 9. و. (جاكارتا : بومى اكسار، الكسارا،

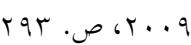


القواعد واللوائح اللازمة لتنفيذ النظام الموحد بانتظام ولا تحيد.

\section{المراجع}

- موحبين شه، فسيكولوجي بلاجار، جيليد با (جاكرتا : راجاجر

$$
\text { افيندو فرسادا، ب ( ا (Y) }
$$

- ايعكوسوارا، الن قمرية، ادمنستراسي فنديديكان، (باندوغ : الفابيتا،

$$
(r \cdot) \cdot
$$

- آنونيم، حيمفونان فروندغ اونداغان ريفبليك إندونيسيا رقم • ت تاهون r r. r عن سيستيم فينديدكان ناسيونال،جيليد 7

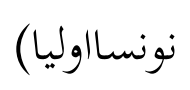

- مهزه مغيلولاكجر داسندالم فمبلاجران، جيليد ا(جاكارتا : بومى اكسارا،

$$
(r \cdot \cdot q
$$

- اوداغ - اوندغ غورو دان دوسين،

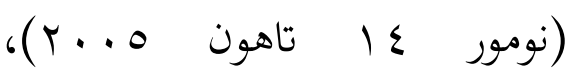

لان تكميله دافع ورافع على رغم التعلم ويكون سهلا للطلاب. ويمكن ان يتحقق المعلم تحققا جيدا على كله حتى لا يكون فيه العقابات والحواجز التى يمكن ان تؤثر على التعلم. والاضافة الى ذلك، يمكن للمستوى الانضباط التى يتم تطبيقها في المدرسة تكون قادرة على تحفيز أنشطة التعلم للطلاب. ويرغم انضباط التعليم في انشطة تعليم التلاميذ. ويف حقيقتها ان عملية التعلم هي التفاعل بين المعلم والتلميذ وبين التلميذ مع التلميذ غيره. وكذلك البيئة بكيث يكون هناك التغيير في السلوك التلميذ نفسه. وفي عملية التعلم، ان الاستاذ يوصف بالمعلم والطالب يوصف بموضوع الدراسة، ويطلب بوجود ملامح تأهيل خاص من حيث المعرفة والقدرات والمواقف والقيم والصفة الشخصية، حتى تمكن العملية ان تتم بفعالية وكفاءة' ه. لان تكون عملية التدريس والتعلم ان تحدث بشكل فعال يلزم فيها الدعائم ليستخدم الاستاذ مع طالبه، ويلزم فيه ايضا

10 سارديمان، إنتيراكسي دان موتيفاسي لبيلاجر

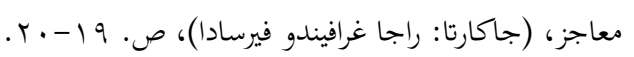


- كشف الانوار اوس دان هيندرا هارمى، فيرينجنأن سيستيم فيمبيلاجران كوريكولوم تيعكات ساتوان فينديديكان، (باندونج:

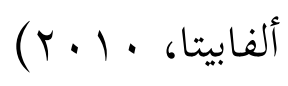

- - سارديمان، إنتيراكسي دان موتيفاسي لبيلاجر معاجز، (جاكارتا: راجا

$$
\text { غرافيندو فيرسادا) }
$$

- عالم فوروانتو، فسيكولوجى فينديديكان، (باندونج : ريماجا

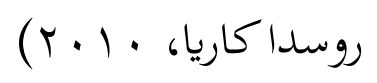

- سيف فيسيكولوجى بيلاجار، ط. لـ

$$
\text { (جاكارتا : ف.ت. رينيكا جيفتا) }
$$

- ي موليشاء، كوريكولوم بيرباسيس كومفيتنسي : كونسيف، كاريكاتيرستيك دان إمفيليمنتاسي، (باندونج : ريماجا روسدا كاريا،

$$
r \cdots r
$$

-
(جاكارتا اسا منديري، جيليد (1)

$$
(r \cdot \lambda
$$

- مرتينيس يامين دان ميسة، مناجمين فمبلاجران كلاس، (جاكارتا: غوغ

$$
\text { فرسادا فريس، } 9 \text { ( . (Y) }
$$

- اينونج فاطمة، فيسيكولوجى فركمباغان فيركمباغان فسرتا ديديك) جيليد با (باندوج

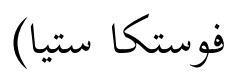
- سيفول سكلا، ادمينستراسي فينديديكان كونتمفورير، جيليد ه، هول،

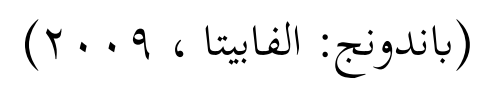

- امام معروف، ستراتيجى فمبلاجران هماسا عرب اكتيف، (سيماراع : نيد

$$
\text { فريس، } 9 \text { ج. (Y) }
$$

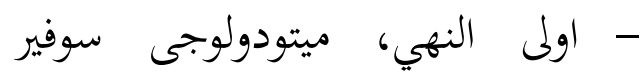

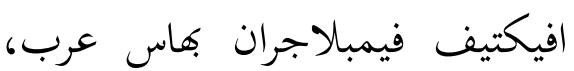

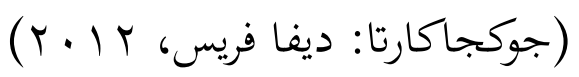
- مصطفي الغلايين، جميع الدروس العربية جزء الاول، (بيروت : دار

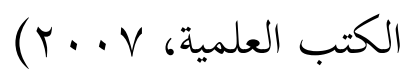


- عبد المعين، اناليسيس كونترا ستيف كماس عرب دان بهاس اندونيسية، (جاكارتا:فوستاكا الحسنى بارو،

$$
(r \cdot \mathcal{L}
$$

- سلاميتو، بيلاجر دان فكتور فكتور يع ميمفيعاروهى، رينيكا

$$
\text { جيفتا، (199) }
$$

- - سوماردي سوريا باتا، فسيكولوجي فينديديكان، (جاكارتا : راجاوالى،

$$
(191 \varepsilon
$$

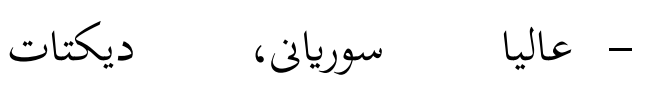

$$
\text { فيسيكولوجي، (11) }
$$

- اودين سيف الدين ساؤد، فيعيمباعان فروفيسي غورو،

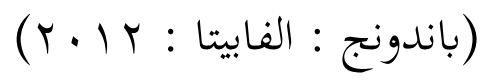

- - سوهرسيمي اريكونتو،

$$
\text { داسار - - داسار ايفالوسي }
$$$$
\text { فينديديكان، ط. } 9 \text { ـ. (جاكارتا }
$$

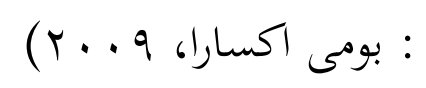

- يوسف الخليفة أبو بكر، منهج التعليم العربية للتعليم الاساسي في دول الساحل الافريقي، إسيسكو، $(r \cdots r$ - - مس ناسوتيون، بيرباغي فينديكاتان دالام فروسيس بيلاجر ميعاجر،

$$
\text { (جاكارتا : بومي أكسارا) }
$$

- - جويريه دخلان، فاراديكما بارو فيمبيلاجران بهاس عرب (كاجيان فراكتيس دان تيورتيس)، (يوكياكارتا ( مومباعسية : - فوروم غوروا بينا ف أإ مدرسة عالية،

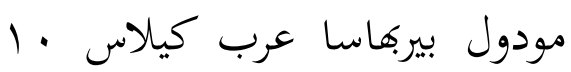

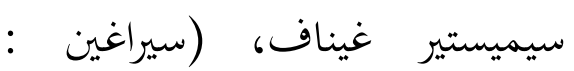
- محمود يونس، قاموس عربي اندونسي، جاكرتا - مابو احمدي دان ويدودو سيفريونو، فسيكولوجى بيلاجار، (جاكرتا : رينيكا جيفتا) -

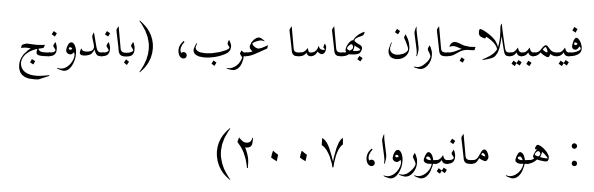

